\title{
COMPARISON OF HYALINE DROPLETS IN RATS WITH CHRONIC PROGRESSIVE NEPHROPATHY AND CHEMICAL-INDUCED $\alpha$ 2u-GLOBULIN NEPHROPATHY
}

\author{
Satoshi Uwagawa, Koichi Saito, Atumi Nakayama, \\ Mitsuyo Umihira, and Yasuyoshi Okuno \\ Environmental Health Science Laboratory, Sumitomo Chemical Co. Ltd.
}

\begin{abstract}
Hyaline droplets in kidney tubules of rats with chronic progressive nephropathy were histopathologically compared with those found in 2,2,4-trimethylpentane (TMP) induced $\alpha 2 \mathrm{u}$-globulin nephropathy. Repeated oral administration of TMP at the dosage of $50 \mathrm{mg} / \mathrm{kg} /$ day for four weeks caused development of hyaline droplets which were all immunohistochemically positive for $\alpha 2 \mathrm{u}-$ globulin. In control rats ( 13 to 52 weeks-old), two types of hyaline droplets were observed : one small round and multiple type being deeply eosinophilic and refractile (hyaline droplet type); and the other being slightly eosinophilic, large, and generally single (eosinophilic body type). Both were positive for anti- $\alpha 2 \mathrm{u}$-globulin immunohistochemical staining. Fifty-two and 109 weeks-old male rats with chronic progressive nephropathy showed "hyaline droplet degeneration" of tubules with hyaline cast formation in the lumina. Immunohistochemical examination revealed such "hyaline droplet degeneration" to be positive for albumin, but negative for $\alpha 2 \mathrm{u}$-globulin. Under the electron microscope, round, amorphous, and moderately electron-dense phagolysosomes were observed in the tubules of "hyaline droplet degeneration" cases, clearly different from the polyangular and crystalline-like electron-dense phagolysosomes of normal $\alpha 2 \mathrm{u}$-globulin reabsorption droplets in young rats or TMP induced $\alpha 2 \mathrm{u}$-globulin accumulation droplets. The present results suggest that the etiology of chronic progressive nephropathy may be somewhat different from that of $\alpha 2 \mathrm{u}$-globulin induced nephropathy in terms of the causative protein. (J Toxicol Pathol 5: 195 203, 1992)
\end{abstract}

Key words: Hyaline droplet, Chronic progressive nephropathy, $\alpha 2 \mathrm{u}-$ Globulin nephropathy, Rat

\section{Introduction}

For toxicity testing of drugs and chemicals, the rat is one of the most commonly used species, especially for long-term toxicity and carcinogenicity studies. With increasing numbers of rats being used in these types of studies, more and more spontaneously occurring disease processes are being encountered. The kidney is a major target organ for induced toxicity by drugs and other chemicals. Therefore, recognition of spon-

宇和川賢 斎藤幸一 中山厚美 海平充代 奥野泰由 Accepted for publication: May 14, 1992

Mailing address: Satoshi Uwagawa, Environmental Health Science Laboratory, Sumitomo Chemical Co. Ltd., 1-98, 3-chome, Kasugadenaka, Konohana-ku, Osaka 554, Japan. taneously occurring kidney lesions and understanding their pathogenesis are naturally necessary for reliable safety assessment of exogenous compounds.

Chronic progressive nephropathy is an important disease of rats because it affects renal function and causes death. Although the histopathological characteristics and factors which affect chronic progressive nephropathy have been reported by several workers, its pathogenesis is still unclear ${ }^{1,2}$. Histopathologically, cast formation in the tubules and thickened basement membranes are the most obvious features of this disease'. Hyaline droplet degeneration is also seen in tubules with hyaline cast formation in chronic progressive nephropathy ${ }^{2}$.

Hyaline droplet accumulation in kidney 
tubules is also very common in conditions other than chronic progressive nephropathy. Droplets are observed in mature male rats, but not in immature males or females of any age. There is evidence that these droplets contain the low molecular weight protein known as $\alpha 2 \mathrm{u}$-globulin ${ }^{1}$. Recently, $C_{10}-C_{11}$ an isoparaffinic solvent ${ }^{3}$, unleaded gasoline $e^{4}$, and isoparaffinic fraction of unleaded gasoline, such as 2,2,4-trimethylpentane $(\mathrm{TMP})^{5,6}, d$-limonene $\mathrm{e}^{7.8}$ and decalin ${ }^{9.10}$ were all reported to induce $\alpha 2 \mathrm{u}$-globulin nephropathy in rat kidneys, characterized by large amounts of $\alpha 2 \mathrm{u}$-globulin accumlated in proximal convoluted tubules (PCT) ${ }^{11,12} . \quad \alpha 2 \mathrm{u}$-Globulin nephropathy occurs only in male rats, because $\alpha 2 \mathrm{u}$-globulin is sex-specific low molecular weight protein ${ }^{13,14}$ which is synthesized in the liver, excreted into urine, and reabsorbed by kidney PCT $^{13,14}$. The $\alpha 2 \mathrm{u}$-globulin content of male rat kidney has been reported to be approximately 120 -fold higher than that of female rat kidney ${ }^{13,14}$.

The purpose of the present study was to investigate the nature of chronic progressive nephropathy associated "hyaline droplet degeneration in tubules" in aged rats, and make comparisons with chemical-induced $\alpha 2 \mathrm{u}$-globulin nephropathy.

\section{Materials and Methods}

\section{Animals and experimental design}

A total of 40 male Sprague-Dawley rats were housed in hanging stainless steel cages (Yamato Chemical Co., Osaka) in an animal room with a $12 \mathrm{~h}$-light, $12 \mathrm{~h}$-dark cycle at $24^{\circ} \mathrm{C}$ and $60 \%$ relative humidity. Food (CRF-1, Oriental Yeast Co., Tokyo) and water were given ad libitum. Experiment 1: Non-treated rats (SLC Japan Inc., Shizuoka) were killed at ages of 13,34, and 52 weeks. Experiment 2: Non-treated rats (Charles River Japan Inc., Atsugi) were killed at 109 weeks. Experiment 3:5-week old male rats (Charles River Japan Inc., Atsugi) were treated with 2, 2, 4trimethylpentane (TMP, Wako Pure Chemical Company, Osaka) $(50 \mathrm{mg} / \mathrm{kg}$ body weight, in corn oil p.o.) 7 days/week for four weeks.

\section{Tissue preparation}

Experiment 1: At the sacrifice time points, the kidneys were immediately removed, fixed by immersion in $10 \%$ neutral buffer formalin, processed routinely, and embedded in paraffin. Two of five rats in each group were anesthetized with pentobarbital and perfused via the aorta with $2 \%$ paraformaldehyde- $1 \%$ glutaraldehyde. The kidneys taken for electron microscopy were further fixed by immersion in $1 \%$ glutaraldehyde after this perfusion fixation, post-fixed in $2 \%$ osmic acid, processed and embedded in Epon 812. Experiment 2: At sacrifice, the kidneys were removed, fixed by immersion in $10 \%$ neutral buffer formalin, processed routinely, and embedded in paraffin. Experiment 3: At the end of the treatment period, rats were anesthetized with pentobarbital and perfused via the aorta with $2 \%$ paraformaldehyde$1 \%$ glutaraldehyde. The kidneys were removed, fixed by immersion in $10 \%$ neutral buffer formalin, and processed routinely. For electron microscopy, kidneys from two of five rats were fixed by immersion in $1 \%$ glutaraldehyde after perfusion fixation and post-fixed in $2 \%$ osmic acid, processed, and embedded in Epon 812.

\section{Light microscopy}

The kidneys were sectioned at $5 \mu \mathrm{m}$ and stained with hematoxylin and eosin (H.E.) as well as the periodic acid-Schiff reaction (PAS), the prussian blue reaction for iron, and the schmorl reaction for lipofuscin. They were also immunohistochemically investigated for binding of anti$\alpha 2 \mathrm{u}-$ globulin and anti-albumin (Organon Teknika Co., West Chester) antibodies using the streptavidinbiotin-alkaline phosphatase complex method (Histofine SAB-AP kit, Nichirei Co., Tokyo). Rabbit anti- $\alpha 2 \mathrm{u}$-globulin-sera were raised against $\alpha 2 \mathrm{u}$-globulin which was isolated and purified from male rat urine ${ }^{15}$.

\section{Electron microscopy}

From the epon blocks, $1 \mu \mathrm{m}$ thin sections on glass slides were stained with toluidine blue for light microscopic selection of appropriate proximal tubule segments. For electron microscopy these selected areas were thin sectioned, mounted, 
and contrasted with uranylacetate and lead citrate. They were then examined under a JEM 1200EX transmission electron microscope.

\section{Results}

Light microscopic examination

\section{Control rats}

Two types of hyaline droplets were observed in PCT epithelial cells, one being deeply eosinophilic and refractile of small round morphology (hyaline droplet type) (Fig. 1, arrow), and the

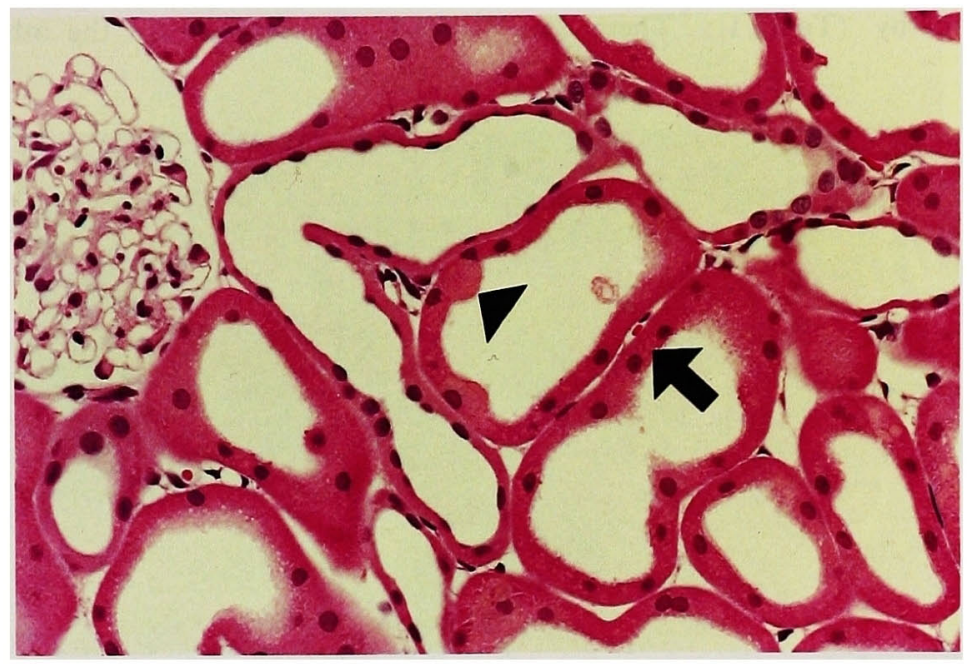

Fig. 1. Kidney of a 13-week-old rat. Two types of hyaline droplets are evident in the PCT epithelial cells, one being deeply eosinophilic and refractile, small, round and multiple (hyaline droplet type) (arrow), and the other being slightly eosinophilic, large, and single (eosinophilic body type) (arrow head). H.E. stain, $\times 300$.

Table 1. Histopathological Findings in the Kidneys of Aged Rats

\begin{tabular}{|c|c|c|c|c|}
\hline \multirow{2}{*}{ Finding } & 13-week & 34-week ${ }^{\mathrm{a}}$ & $52-$ week $^{a}$ & 109-week ${ }^{b}$ \\
\hline & 5 & 5 & 5 & 10 \\
\hline \multicolumn{5}{|l|}{ Glomerulus } \\
\hline Degeneration & $0(0.0)$ & $0(0.0)$ & $1(1.0)$ & $9(1.1)$ \\
\hline \multicolumn{5}{|l|}{ Renal tubules } \\
\hline Hyaline droplet formation & $5(2.0)$ & $5(1.6)$ & $5(1.4)$ & $0(0.0)$ \\
\hline Eosinophilic body formation & $5(1.8)$ & $5(1.0)$ & $5(1.0)$ & $0(0.0)$ \\
\hline Hyaline droplet degeneration & $0(0.0)$ & $0(0.0)$ & $1(1.0)$ & $10(1.0)$ \\
\hline Degeneration/regeneration & $3(1.0)$ & $5(1.0)$ & $5(1.4)$ & $10(2.4)$ \\
\hline Hyaline cast formation in tubules & $0(0.0)$ & $4(1.0)$ & $4(1.3)$ & $10(1.6)$ \\
\hline Brown pigment deposition & $0(0.0)$ & $1(1.0)$ & $5(1.4)$ & $9(1.5)$ \\
\hline \multicolumn{5}{|l|}{ Other } \\
\hline Mononuclear cell infiltration & $5(1.0)$ & $3(1.0)$ & $5(1.2)$ & $10(1.5)$ \\
\hline
\end{tabular}

a ; experiment $1, b$; experiment 2

Data in parentheses indicate the mean grade of severity of the findings : individual animals graded 1 ; minimal, 2 ; slight, 3 ; moderate, 4 ; severe 
other being moderately eosinophilic, enlarged, and single (eosinophilic body type) (Fig. 1, arrow head). Both were observed at all age of rats investigated, although they were prominent in 13week-old rats and tended to decrease with aging (Table 1). Fifty-two-week-old rats and 109week-old rats demonstrated brown pigment in the tubules, tubular degeneration and regeneration with thickened basement membranes, hyaline cast formation, glomerulus degeneration, and interstitial mononuclear infiltration, indicating chronic progressive nephropathy (Table 1). These rats were also characterized by "hyaline droplet degeneration" of tubules with hyaline cast formation, the hyaline droplets in such cases being deeply eosinophilic and refractile. These were generally larger than the hyaline droplets type observed in younger animals but smaller than the eosinophilic bodies (Fig. 2).

Immunohistochemical examination revealed both of hyaline droplets (hyaline droplet and eosinophilic body types) to be anti- $\alpha 2 \mathrm{u}$-globulin positive (Fig. 3), either negative or positive for PAS, and negative for the other stains (Fig. 4).

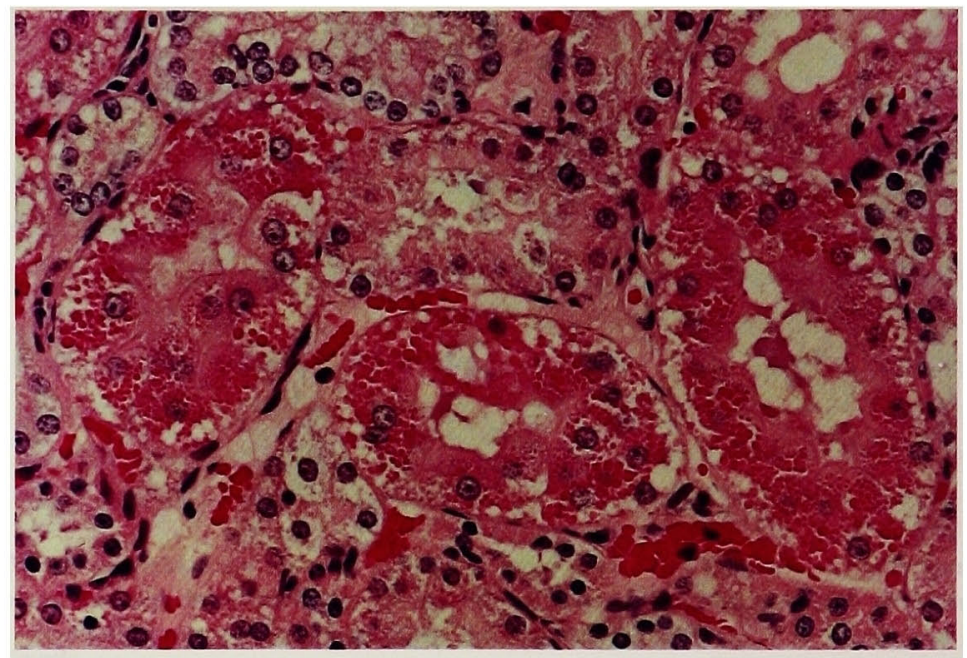

Fig. 2. Kidney of a 109-week-old rat. Deeply eosinophilic refractile cytoplasmic inclusions are evident in tubules demonstrating "hyaline droplet degeneration". H.E. stain, $\times 300$.

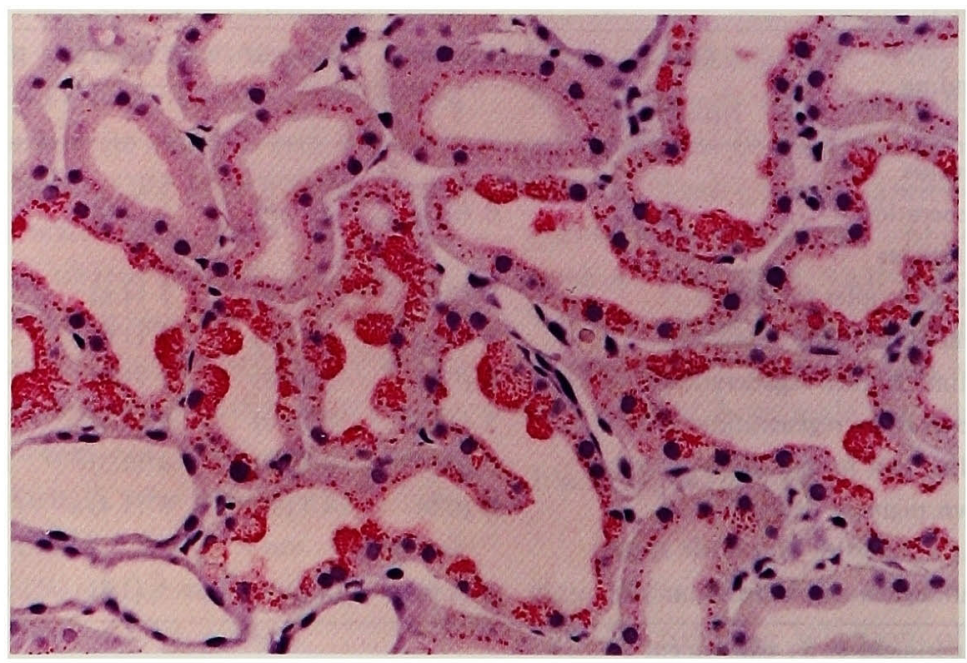

Fig. 3. Kidney of a 13-week-old rat: Both types of hyaline droplets (hyaline droplet and eosinophilic body) are positive for anti- $\alpha 2 \mathrm{u}$-globulin immunohistochemical staining. $\times 300$. 


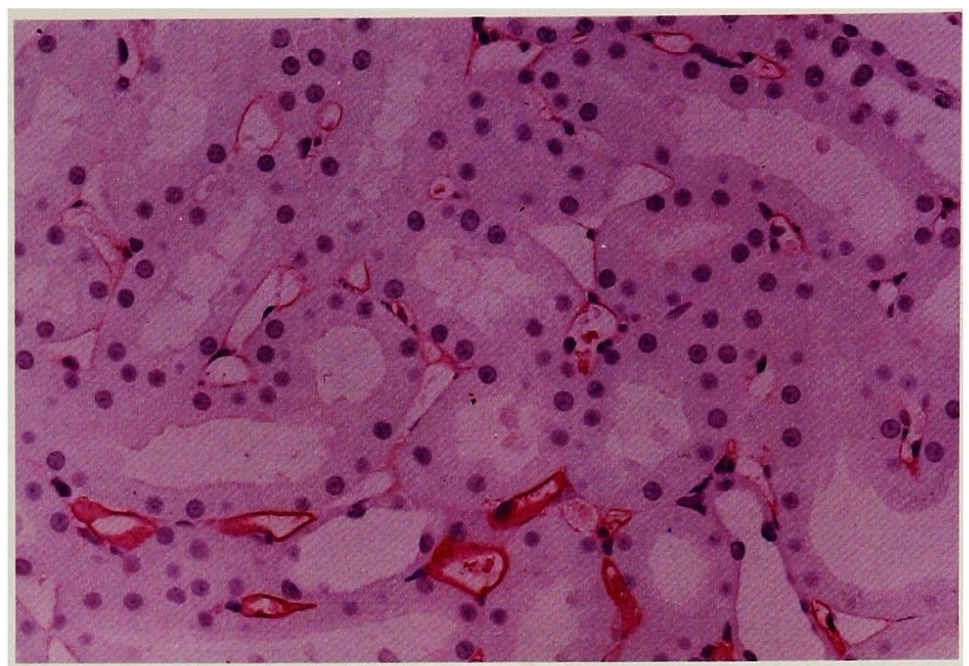

Fig. 4. Kidney of a 13-week-old rat. Both types of hyaline droplets (hyaline droplet and eosinophilic body) are negative for anti-albumin immunohistochemical staining. $\times 300$.

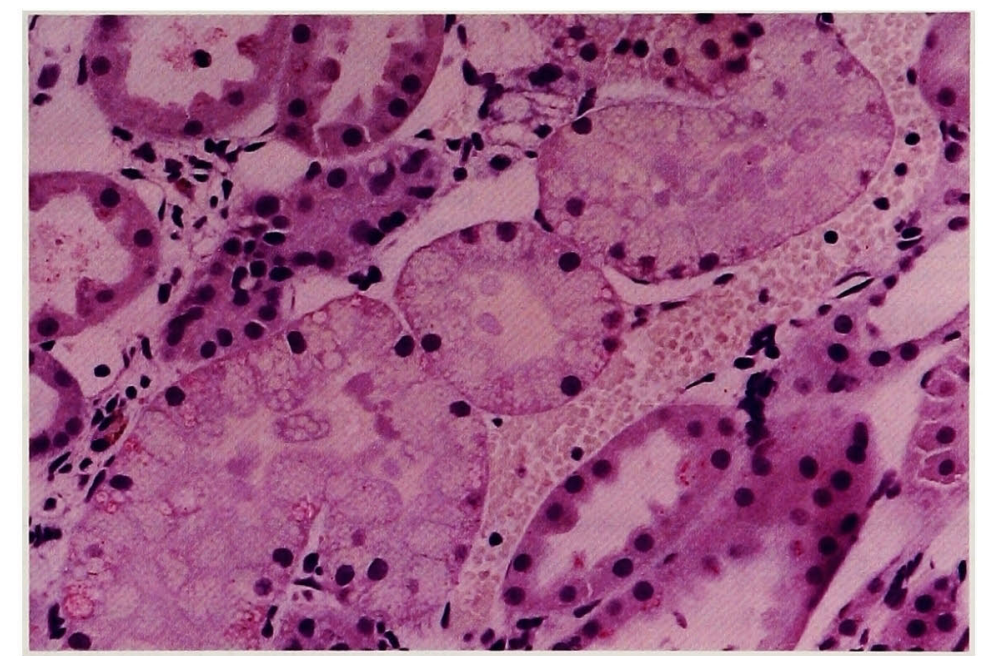

Fig. 5. Kidney of a 109-week-old rat. Hyaline droplets in "hyaline droplet degeneration" are negative for anti- $\alpha 2 \mathrm{u}$-globulin immunohistochemical staining. $\times 300$.

On the other hand, hyaline droplets in "hyaline droplet degeneration" cases were negative for anti$\alpha 2 u$-globulin (Fig. 5), positive for antialbumin (Fig. 6) and the PAS reaction, and negative for either prussian blue or schmorl reaction (Table 2). 2. TMP treated rats

In rats treated with TMP for 4 weeks, numerous hyaline droplets (both hyaline droplet and eosinophilic body types) were accumulated in the PCT epithelial cells. Although hyaline droplets were occasionally observed in the kidneys of control rats, they were far less prominent. In addi- tion, the droplets in rats treated with TMP were substantially larger than those of controls. Necrotic cell debris as granular casts was also observed in the lumina of the dilated tubules at the corticomedullary junction. Such degeneration and associated regenerative PCT epithelial cells characterized by cytoplasmic basophilia and tubular thickening of the basement membranes were more evident in treated than in control rats (Table 3). TMP associated hyaline droplets were positive for $\alpha 2 \mathrm{u}$-globulin immunohistochemical staining (Table 2). 


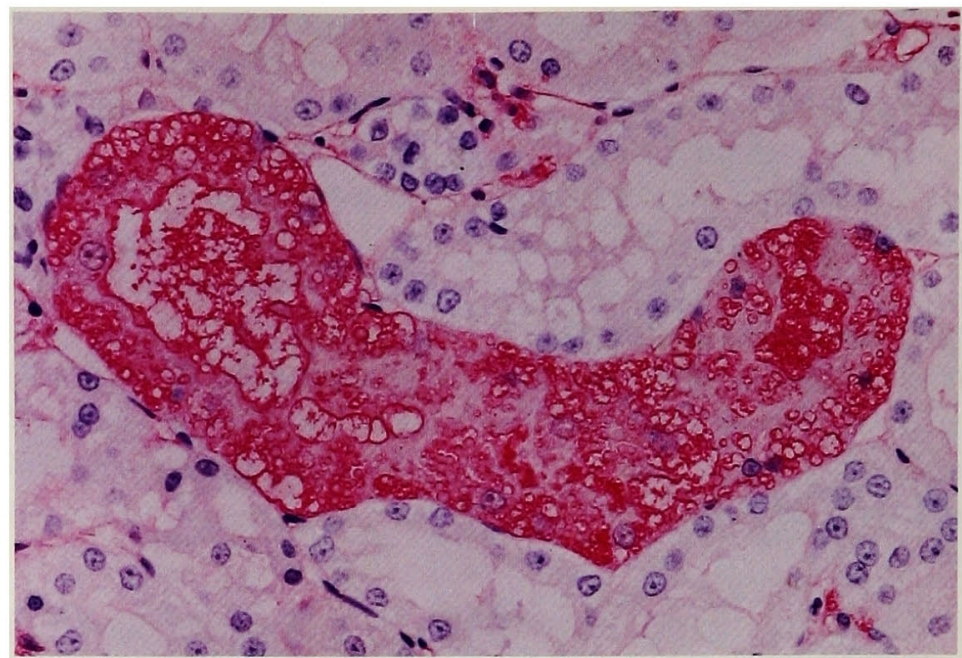

Fig. 6. Kidney of a 109-week-old rat. Hyaline droplets in "hyaline droplet degeneration" are strongly positive for anti-albumin immunohistochemical staining. $\times 300$.

Table 2. Summary of Histochemical and Immunohistochemical Kidney Findings

\begin{tabular}{lcccc}
\hline \multicolumn{1}{c}{ Staining } & \multicolumn{2}{c}{$\begin{array}{c}\text { Spontaneous } \\
\text { hyaline droplet }\end{array}$} & $\begin{array}{c}\text { TMP } \\
\text { associated } \\
\text { hyaline } \\
\text { droplet }\end{array}$ & $\begin{array}{c}\text { Chronic } \\
\text { nephropathy }\end{array}$ \\
\cline { 2 - 5 } & $\begin{array}{c}\text { Hyaline } \\
\text { droplet } \\
\text { type }\end{array}$ & $\begin{array}{c}\text { Eosinophilic } \\
\text { body } \\
\text { type }\end{array}$ & & $\begin{array}{c}\text { Hyaline } \\
\text { droplet } \\
\text { degeneration }\end{array}$ \\
\hline Eosin & + & + & + & + \\
Periodic acid-Schiff & $-/+$ & $-/+$ & $-/+$ & \pm \\
Prussian blue & - & - & - & - \\
Schmorl & + & - & - & - \\
Anti- $\alpha$ 2u-globulin & - & - & - & + \\
Anti-albumin & - & - & - & - \\
\hline
\end{tabular}

- : negative, $-/+$ : negative or positive, \pm : weakly positive, $+:$ positive

Table 3. Histopathological Findings in the Kidneys of Rats Treated with TMP for 4 Weeks

\begin{tabular}{lcc}
\hline \multicolumn{1}{c}{$\begin{array}{c}\text { Group } \\
\text { No. of rats }\end{array}$} & Control & TMP $50 \mathrm{mg} / \mathrm{kg}$ \\
\cline { 2 - 3 } & 10 & 10 \\
\hline Renal tubules & $10(1.0)$ & $10(3.7)$ \\
\hline Hyaline droplets/eosinophilic bodies & $8(1.0)$ & $10(1.6)$ \\
Degeneration/regeneration & $0(0.0)$ & $1(1.0)$ \\
Necrotic cell debris & $1(1.0)$ & $0(0.0)$ \\
Fibrosis & $9(1.0)$ & $9(1.1)$ \\
Other & & \\
\hline
\end{tabular}

Data in parentheses indicate the mean grade of severity of the findings : individual animals graded 1; minimal, 2 ; slight, 3 ; moderate, 4 ; severe 


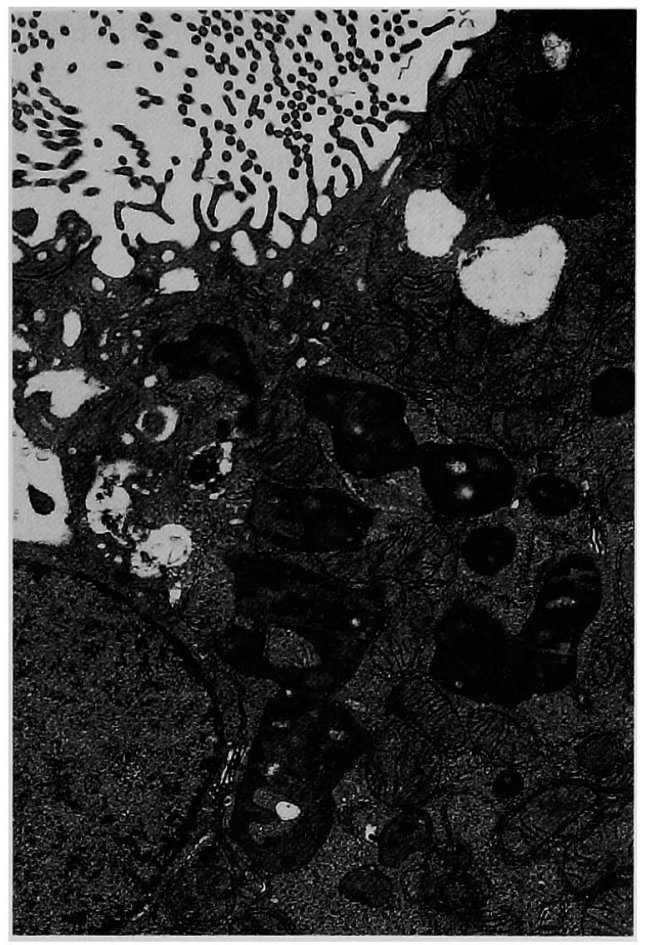

Fig. 7. Electron microscopic appearance of a kidney proximal tubule cell from a 13-week-old rat. Polyangular and crystalline-like electrondense phagolysosomes are observed. $\times 10,000$.

\section{Electron microscopic examination}

\section{Control rats}

Three types of phagolysosomes were observed in control rats. Firstly, at all ages, polyangular and crystalline-like electron-dense phagolysosomes were observed in the PCT epithelial cells. However, these phagolysosomes were smaller and fewer than those observed after TMP treatment (Fig. 7). Secondly, round and amorphous moderately electron-dense phagolysosomes (Fig. 8, arrow) along with clear vacuoles (Fig. 8 , arrow head) were observed in the tubules of "hyaline droplet degeneration" cases with chronic progressive nephropathy. Thirdly, 34-, and 52-week-old rats demonstrated residual bodies which contained high density granules as inner structures (Fig. 9).

\section{TMP treated rats}

Only polyangular and crystalline-like electron-dense phagolysosomes, larger than in the control case, were observed in PCT epithelial cells (Fig. 10). Other orgnelles such as mitochondria,

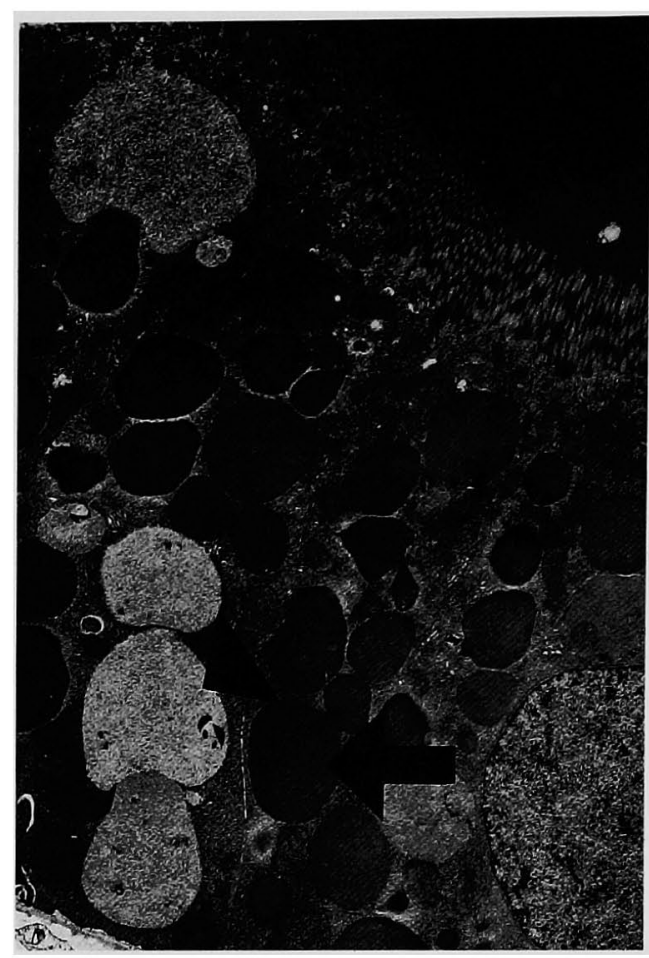

Fig. 8. Electron microscopic appearance of a kidney proximal tubule cell from a 109 -week-old rat. Round and amorphous, moderately electron-dense phagolysosomes (arrow) and vacuoles (arrow head) are observed in a case of "hyaline droplet degeneration" with chronic progressive nephropathy. $\times 6,000$.

smooth endoplasmic reticulum, and nucleus were normal in TMP-treated rats.

\section{Discussion}

The present investigation demonstrated that PCT cells containing hyaline droplets in young rats can be divided into two types, the dominant one being deeply eosinophilic and refractile, and small round morphology (hyaline droplet type), the second was found singly, being enlarged and more moderately eosinophilic (eosinophilic body type). Peter ${ }^{1}$ also reported two types of hyaline droplets in mature male rat kidney. However, immunohistochemical examination indicated that in our case both droplets were positive for anti$\alpha 2 \mathrm{u}$-globulin immunohistochemical staining. Since $50 \%$ of the $\alpha 2 \mathrm{u}$-globulin synthesized in the liver and excreted into urine were reabsorbed in 


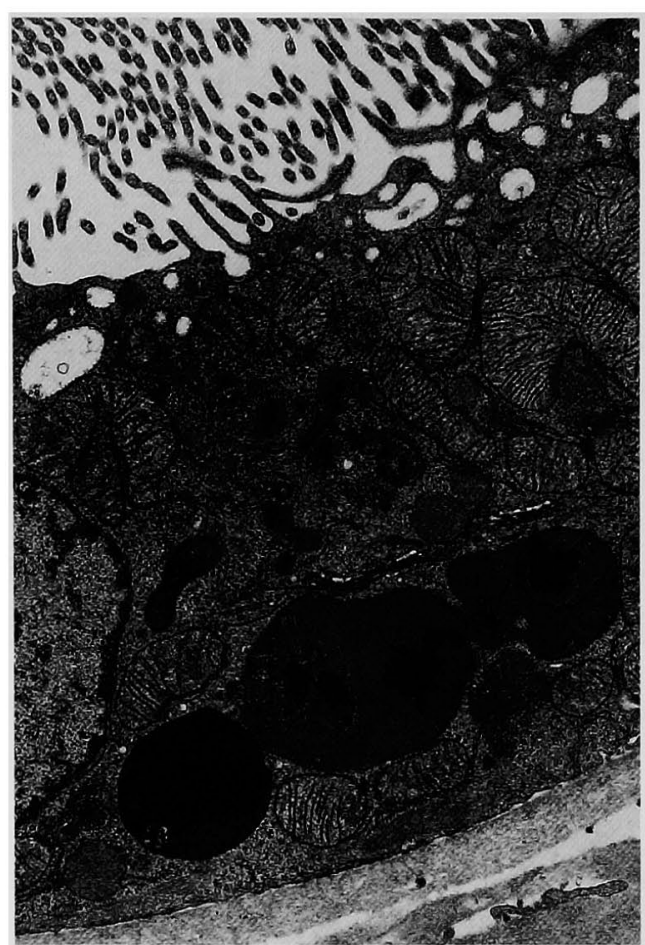

Fig. 9. Ultrastructural detail of polymorphic lysosomes containing high density granules (residual body) observed in a PCT epithelial cell of a 52-week-old rat. $\times 10,000$.

the kidney ${ }^{13,14}$, these two types of hyaline droplets are presumably only indicative of the normal biology of $\alpha 2 \mathrm{u}$-globulin processing in male rats. The fact that such $\alpha 2 \mathrm{u}$-globulin positive hyaline droplets tended to decrease with age is in line with the reported reduction in $\alpha 2 \mathrm{u}$-globulin synthesis in the liver after 100 days of age ${ }^{16}$.

In contrast, histopathological examination revealed that brown pigment in the tubules, tubular degeneration and regeneration with thickened basement membranes, hyaline cast formation, glomerulus degeneration, and interstitial mononuclear infiltration, indicative of chronic progressive nephropathy, were increased in 52-, and 109week-old rats. The Sprague-Dawley strain rat is considered to be one of the most susceptible strains to chronic progressive nephropathy with the disease occurring in $29.6 \%$ of 52 -week-old male rats ${ }^{1}$. Our results are in agreement with previous reports ${ }^{1,2}$.

The present immunohistochemical examination revealed that the hyaline droplet in cases of

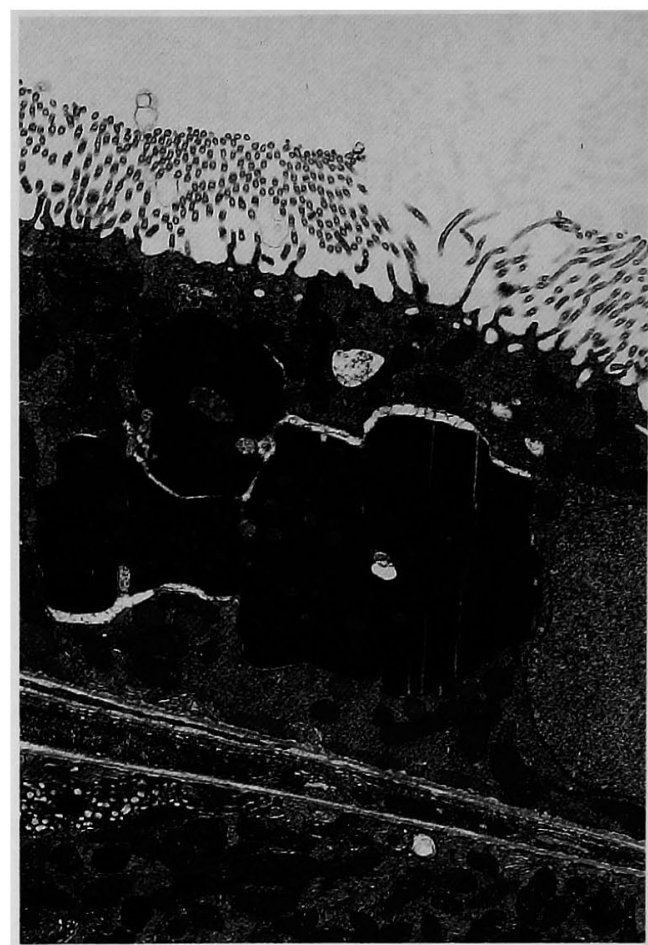

Fig. 10. Ultrastructural detail of polyangular and crystalline-like electron-dense phagolysosomes observed in a PCT epithelial cell after TMP treatment. $\times 6,000$.

"hyaline droplet degeneration" were weakly positive for albumin, but completely negative for $\alpha 2 \mathrm{u}$ globulin. In addition the electron microscopic appearance of the round and amorphous moderately electron-dense phagolysosomes and vacuoles observed in the affected tubules contrasted sharply from that of normal $\alpha 2 \mathbf{u}$-globulin reabsorption droplets and TMP induced $\alpha 2 \mathrm{u}$-globulin accumulation droplets which were polyangular, crystalline-like, and electron-dense. "Hyaline droplet degeneration" with chronic progressive nephropathy in which the droplets were also weakly positive with albumin and negative with $\alpha 2 \mathrm{u}-$ globulin has also been observed in female rats (unpublished observations, S. Uwagawa). Investigation of the early stages of chronic progressive nephropathy indicated that the involved thickening of the basement membrane of the glomerular capillary loops, Bowman's capsule, and proximal tubules, is initiated in individual nephrons ${ }^{1,2}$. Losses of protein such as albumin are increased in these affected nephrons ${ }^{1,2,17}$ and diets with a high 
protein content cause an earlier development of the disease $^{1,2}$. Our results taken in conjunction with earlier findings thus suggest accumulation of a protein such as albumin is one of the determining factor for renal tubule degeneration in chronic progressive nephropathy.

In conclusion, we propose that "hyaline droplet degeneration" with chronic progressive nephropathy is related to albumin accumulation in the epithelial cells, in contrast to the $\alpha 2 \mathrm{u}$-globulin involved in chemical induced $\alpha 2 \mathrm{u}$-globulin nephropathy in rats which is itself due to dysfunction of normal $\alpha 2 \mathrm{u}$-globulin absorption (hyaline droplet and eosinophilic body).

Acknowledgments : The authors thank Mr. Tadashi Noda, Mr. Yasunori Katsura and Miss. Chinami Inamatsu for their valuable technical assistance.

\section{References}

1. Peter, CP, Burek, JD, and van Zwieten, MJ : Spontaneous nephropathies in rats. Toxicol Pathol 14: 91-100, 1986.

2. Gray, JE: Chronic progressive nephrosis in the albino rat. CRC Crit Rev Tox 5 : 115-144, 1977.

3. Phillip, RD and Cockrell, BY : Kidney structural changes in rats following inhalation exposure to $\mathrm{C}_{10}-\mathrm{C}_{11}$ isoparaffinic solvent. Toxicology 33 : 261-273, 1984.

4. Olson, MJ, Garg, BD, Murty CVR, and Roy, AK : Accumulation of $\alpha 2 \mathrm{u}$-globulin in the renal proximal tubules of male rats exposed to unleaded gasoline. Toxicol Appl Pharmacol 90 : 43-51, 1987.

5. Lock, EA, Charbonneau, M, Strasser, J, Swenberg JA, and Bus, JS : Light hydrocarbon-induced nephrotoxicity: The interaction of 2,2,4-trimethylpentane with alpha-2u-globulin in the rat kidney. In : Nephrotoxicity, In Vitro to In Vivo, Animal to Man, PH Bach and EA Lock Eds, Plenum Press, New York, 1989.

6. Lock, EA : Chronic nephrotoxicity of 2, 2, 4trimethylpentane and other branched-chain hydrocarbons. Toxicology 53: 75-80, 1990.

7. Kanerva, RL, Ridder, GM, Lefever FR, and Alden,
$C L$ : Comparison of short-term renal effects due to oral administration of decalin or $d$-limonene in young adult male Fischer-344 rats. Food Chem Toxic 25 : 345-353, 1987.

8. Kanerva, RL and Alden, CL: Review of kidney sections from a subchronic $d$-limonene oral dosing study conducted by the National Cancer Institute. Food Chem Toxic 25: 355-358, 1987.

9. Stone, LC, Kanerva, RL, Burns, JL, and Alden, CL : Decalin induced nephrotoxicity : Light and electron microscopic examination of the effects of oral dosing on the development of kidney lesions in the rat. Food Chem Toxic 25 : 43-52, 1987.

10. Kanerva, RL, McCracken, MS, Alden, CL, and Stone, LC: Morphogenesis of decalin-induced renal alterations in the male rat. Food Chem Toxic 25 : 53-61, 1987.

11. Short, BG, Burnett, VL, Cox, MG, Bus, JS, and Swenberg, JA : Site-specific renal cytotoxicity and cell proliferation in male rats exposed to petroleum hydrocarbons. Lab Invest 57 : 564-577, 1987.

12. Short, BG, Burnett, VL, and Swenberg, JA : Histopathology and cell proliferation induced by 2,2 , 4-trimethylpentane in the male rat kidney. Toxicol Pathol 14: 194-203, 1986.

13. Borghoff, SJ, Short, BG, and Swenberg, JA : Biochemical mechanisms and pathobiology of $\alpha 2 \mathrm{u}-$ globulin nephropathy. Annu Rev Pharmacol Toxicol 30 : 349-367, 1990.

14. Swenberg, JA, Short, B, Borghoff, S, Strasser, J, and Charbonneau, $\mathbf{M}$ : The comparative pathology of $\alpha 2 \mathrm{u}$-globulin nephropathy. Toxicol Appl Pharmacol $97:$ 35-46, 1989.

15. Saito, K, Uwagawa, S, Kaneko, H, and Yoshitake, A : Behavior of $\alpha 2 \mathrm{u}$-globulin accumulation in kidneys of male rats treated with $d$-limonene: Kidneytype $\alpha 2 \mathrm{u}$-globulin in the urine as a marker of $d$ limonene nephropathy. Toxicology 79: 173-183, 1991.

16. Roy, AK, Nath, TS, Motwani, NM, and Chatterjee, $B$ : Age dependent regulation of the polymorphic forms of $\alpha 2 \mathrm{u}$-globulin. J Biol Chem 258 : 1012310127, 1983.

17. Dodane, V, Chevalier, J, Bariety, J, Pratz, J, and Corman, B : Longitudinal study of solute excretion and glomerular ultrastructure in an experimental model of aging rats free of kidney disease. Lab Invest 64: 377-391, 1991. 